\title{
Experimental study on the impact of water on rock compressive strength
}

\author{
ZHANG Yanbo ${ }^{1,2}$, LIU Cuiping ${ }^{1,2}$, LIANG Peng ${ }^{1,2}$, LIU Xiangxin ${ }^{1,2}$, TIAN
}

Baozhu ${ }^{1,2}$

\begin{abstract}
( ( 1.College of Mining Engineering, North China University of Science and Technology, Tangshan, Hebei 063009,China;2.Hebei Province mining industry develops with safe technology priority laboratory, Tangshan 063009, China )
\end{abstract}

Key words: water; mass fraction; compressive strength; rate of change

Abstract: In order to study the effect of water on the rock compressive strength, mechanical data for different water content of siltstone uniaxial loading process are analyzed, the results show that: 1) siltstone compressive strength decreases as the water content is increased, the damage of water to siltstone with increasing moisture content increases. 2) The water mass fraction $2.551 \%$ is a key point of the impact of water to the siltstone strength change rate. Below $2.551 \%$, with the mass fraction of water increases the compressive strength of sandstone decrease rate increases; higher than $2.551 \%$, with the mass fraction of water increases the compressive strength of siltstone decrease rate reduced.

\section{Introduction}

As is known to all, groundwater is one of the factors that affect the coal mine safety production. Rock is deformable porous media, after water effect, it will cause changes in certain physical, chemical and mechanical properties, the problem of swelling rock, strength reduction has been a problem troubled the surrounding rock stability of underground engineering ${ }^{[1-3]}$. The existing engineering practice tell people that even small tunnel water seepage can also make a lot damage to the surrounding rock of roadway and bring great difficulty to maintenance of roadway ${ }^{[4]}$. And the existing research results show that water has a significant influence on rock yield strength, the yield strength of rock with water pressure increases almost linearly decreases ${ }^{[5]}$. But rock yield strength variation with moisture content has not been reported.

In order to investigate the effect of water on rock strength, this paper chose the high porosity of siltstone dealing with different moisture content to study the relationship of rock uniaxial compressive strength and the changes of moisture content. In this paper, the results for coal mine safety in production are of important reference value and theoretical significance.

\section{Experimental Design}

\section{Experimental equipment}

Loading device is adopted in the experiment for TAW - 3000 rock mechanics test system. It adopt advanced testing machine control technology at home and abroad and can realize drawing the whole loading process. The experiment site is shown in figure 1. 


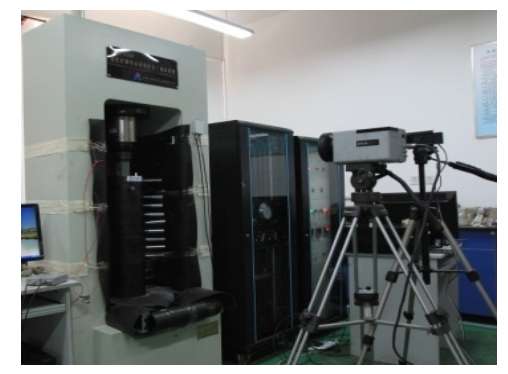

Fig 1 the experiment site

\section{Preparation of test pieces}

The sandstone rock are made as $50 \mathrm{~mm}$ x $50 \mathrm{~mm}$ x $100 \mathrm{~mm}$ (length $\mathrm{x}$ width $\mathrm{x}$ height) standard rectangle sample. The sample two ends surface flatness error is less than $0.05 \mathrm{~mm}$. Put prepared sample into the oven for drying, then the sample is divided into six groups (1-6) dealing with different moisture content. Different moisture content is put dried powder sandstone sample in the set standard of temperature and humidity box. Specimen basic parameters are shown in table 1.

Table 1 Sample Number and moisture content

\begin{tabular}{|c|c|c|c|c|c|}
\hline $\begin{array}{l}\text { sample } \\
\text { number }\end{array}$ & $\begin{array}{l}\text { Original } \\
\text { Weight } \\
(\mathrm{Kg})\end{array}$ & $\begin{array}{c}\text { Dry } \\
\text { weight } \\
(\mathrm{Kg})\end{array}$ & $\begin{array}{c}\text { Water } \\
\text { weight }(\mathrm{Kg})\end{array}$ & $\begin{array}{c}\text { moisture } \\
\text { content }\end{array}$ & $\begin{array}{c}\text { average } \\
\text { moisture } \\
\text { content }\end{array}$ \\
\hline $1-1$ & 0.669 & 0.663 & - & $0 \%$ & \multirow{3}{*}{$0 \%$} \\
\hline $1-2$ & 0.672 & 0.667 & - & $0 \%$ & \\
\hline $1-3$ & 0.562 & 0.557 & - & $0 \%$ & \\
\hline $2-1$ & 0.693 & 0.689 & 0.696 & $1.016 \%$ & \multirow{4}{*}{$1.099 \%$} \\
\hline $2-2$ & 0.685 & 0.68 & 0.687 & $1.029 \%$ & \\
\hline $2-3$ & 0.681 & 0.681 & 0.689 & $1.175 \%$ & \\
\hline $2-4$ & 0.685 & 0.68 & 0.688 & $1.176 \%$ & \\
\hline $3-1$ & 0.668 & 0.663 & 0.673 & $1.508 \%$ & \multirow{4}{*}{$1.438 \%$} \\
\hline $3-2$ & 0.665 & 0.66 & 0.67 & $1.515 \%$ & \\
\hline $3-3$ & 0.667 & 0.662 & 0.671 & $1.360 \%$ & \\
\hline $3-4$ & 0.663 & 0.657 & 0.666 & $1.370 \%$ & \\
\hline $4-1$ & 0.553 & 0.55 & 0.564 & $2.545 \%$ & \multirow{4}{*}{$2.551 \%$} \\
\hline $4-2$ & 0.643 & 0.637 & 0.654 & $2.669 \%$ & \\
\hline $4-3$ & 0.643 & 0.637 & 0.653 & $2.512 \%$ & \\
\hline $4-4$ & 0.653 & 0.646 & 0.662 & $2.477 \%$ & \\
\hline $5-1$ & 0.644 & 0.636 & 0.655 & $2.987 \%$ & \multirow{4}{*}{$3.102 \%$} \\
\hline $5-2$ & 0.645 & 0.637 & 0.657 & $3.140 \%$ & \\
\hline $5-3$ & 0.644 & 0.636 & 0.656 & $3.145 \%$ & \\
\hline $5-4$ & 0.644 & 0.638 & 0.658 & $3.135 \%$ & \\
\hline $6-1$ & 0.639 & 0.629 & 0.655 & $4.134 \%$ & \multirow{3}{*}{$4.035 \%$} \\
\hline $6-2$ & 0.639 & 0.63 & 0.654 & $3.810 \%$ & \\
\hline $6-3$ & 0.635 & 0.625 & 0.651 & $4.160 \%$ & \\
\hline
\end{tabular}

\section{Experimental Methods}

In this paper, uniaxial loading use of test of displacement control. The loading rate is $0.2 \mathrm{~mm} /$ min, the whole process curves recorded during loading. 


\section{analyses of experimental results}

\section{Mechanical Curve Analysis}

Load - time curve of siltstone rock sample under uniaxial compression reflects the mechanical properties of powder sandstone sample. By the test results, the different moisture content of siltstone sample load - time curve as shown in figure 2.

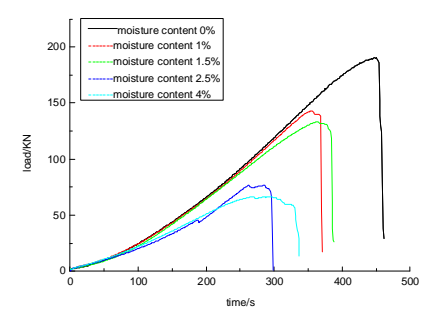

Fig2 different water contents siltstone load - time curve

As it can be seen from figure 2, different moisture content of siltstone in the whole process of deformation and failure load - time curve form are similar. Both experienced early loading curve downward bending, after compaction is linear elastic stage, the stage of yield before peak load and peak load curve after by stages. But different moisture content of sample in each stage has different deformation features: siltstone maximum strength in a dry state, the whole process lasted for a long time to load, large deformation, linear elastic stage of long duration, short plastic stage and a small degree of bending curve. Powder sandstone at the start of loading after the water load - time curve soon produce visible bends, short duration of the whole loading process and the elastic deformation stage time is short, the shorter and more moisture content of the elastic deformation stage, on the contrary, the plastic phase, the longer the duration curve bending degree. Peak load of each sample is shown in table 2. 
Table 2 Sample Peak Load

\begin{tabular}{|c|c|c|c|c|}
\hline $\begin{array}{l}\text { sample } \\
\text { number }\end{array}$ & $\begin{array}{l}\text { moisture } \\
\text { content }\end{array}$ & $\begin{array}{l}\text { average } \\
\text { moisture content }\end{array}$ & $\begin{array}{l}\text { peak load } \\
(\mathrm{KN})\end{array}$ & $\begin{array}{c}\text { average peak load } \\
(\mathrm{KN})\end{array}$ \\
\hline $1-1$ & $0 \%$ & \multirow{3}{*}{$0 \%$} & 190.42 & \multirow{3}{*}{155.21} \\
\hline $1-2$ & $0 \%$ & & 169.64 & \\
\hline $1-3$ & $0 \%$ & & 120 & \\
\hline $2-1$ & $1.016 \%$ & \multirow{4}{*}{$1.099 \%$} & 145.68 & \multirow{4}{*}{143.165} \\
\hline $2-2$ & $1.029 \%$ & & 138.59 & \\
\hline $2-3$ & $1.175 \%$ & & 145.52 & \\
\hline $2-4$ & $1.176 \%$ & & 142.87 & \\
\hline $3-1$ & $1.508 \%$ & \multirow{4}{*}{$1.438 \%$} & 130.82 & \multirow{4}{*}{133.885} \\
\hline $3-2$ & $1.515 \%$ & & 131.9 & \\
\hline $3-3$ & $1.360 \%$ & & 139.35 & \\
\hline $3-4$ & $1.370 \%$ & & 133.47 & \\
\hline $4-1$ & $2.545 \%$ & \multirow{4}{*}{$2.551 \%$} & 66.9 & \multirow{4}{*}{76.035} \\
\hline $4-2$ & $2.669 \%$ & & 76.39 & \\
\hline $4-3$ & $2.512 \%$ & & 76.96 & \\
\hline $4-4$ & $2.477 \%$ & & 83.89 & \\
\hline $5-1$ & $2.987 \%$ & \multirow{4}{*}{$3.102 \%$} & 73.81 & \multirow{4}{*}{74.99} \\
\hline $5-2$ & $3.140 \%$ & & 75.71 & \\
\hline $5-3$ & $3.145 \%$ & & 80.65 & \\
\hline $5-4$ & $3.135 \%$ & & 69.79 & \\
\hline $6-1$ & $4.134 \%$ & \multirow{3}{*}{$4.035 \%$} & 63.81 & \multirow{3}{*}{74.31} \\
\hline $6-2$ & $3.810 \%$ & & 92.42 & \\
\hline $6-3$ & $4.160 \%$ & & 66.71 & \\
\hline
\end{tabular}

The above data show that from the dry state to a water content of $1 \%$, the peak load siltstone down from $190.42 \mathrm{KN}$ to $142.87 \mathrm{KN}$, siltstone peak load reduced by $25 \%$, or $25 \%$ lower uniaxial compressive strength. when siltstone the water content of $1.5 \%$, siltstone peak load of $133.47 \mathrm{KN}$, this time with a dry state siltstone strength is reduced as compared 29.90\%; when water siltstone sample was $2.5 \%$, the siltstone the peak load is $76.96 \mathrm{KN}$, compared with a dry state coal intensity decreased 59.6 percent; when the water content was $4.0 \%$ of the sample siltstone, siltstone peak load is $66.71 \mathrm{KN}$, and dry state coal sample strength compared to 65 percent lower. Hydraulics damage to siltstone increases with moisture content increasing.

Analysis of water on the strength of the impact of siltstone

To study the degree of intensity changes with the moisture content of siltstone, analyses the experimental data, the moisture content and the peak load of the sample were averaged, draw the peak load curve along with the change of moisture content, as is shown in figure 3 .

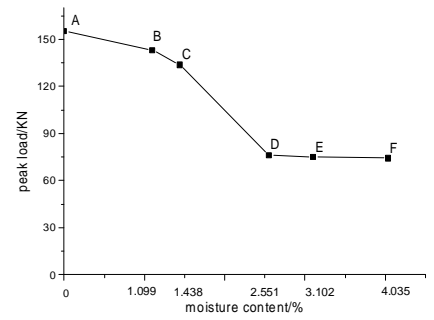

Fig 3 curve of peak load change with moisture content 
As is seen from figure 3, the peak load of siltstone gradually reduces with the increase of moisture content. The strength of siltstone reduces after water, but it is not a uniform reduction process. When the moisture content is less than $1.438 \%$, siltstone compressive strength is larger; after more than $1.438 \%$, the compressive strength is decreased obviously. At the same time, moisture content is less than $2.551 \%$ the compressive strength reduce soon, after more than $2.551 \%$, the trend slowed. Compressive strength decrease speed with the moisture content can be said with every line of the slope, calculated $\mathrm{AB}$ section of the slope is 10.96; BC section 27.37; CD section 51.98; DE section 1.90; EF section 0.729. Water on the Rocks played a softening effect,the softening rate under different moisture content is different. When moisture content is less than $2.551 \%$, with the increase of moisture softening effect is more obvious, that is the higher the moisture content is in the case of same amount changes the peak load reduces the faster. When moisture content is higher than $2.551 \%$, the increase of moisture content the softening effect is abate, that is the higher the moisture content is in the case of same amount changes the peak load reduces the slower. When the water content is between $1.438 \%$ and $2.551 \%$, peak load reduce rate fastest with the moisture content increases. At this point the weakening effect of water to the rocks is most obvious, the most obvious changes of water on rock strength.

\section{conclusions}

(1) Different moisture content of siltstone in the whole process of deformation and failure load - time curve form is similar, but with the increase of moisture content of siltstone linear elastic stage shorter, the plastic phase of longer.

(2) Siltstone compressive strength with increasing moisture content decreased the hydraulics damage to siltstone with increasing moisture content increases.

(3) The water mass fraction $2.551 \%$ is a key point of the impact of water to the siltstone strength change rate. Below $2.551 \%$, with the mass fraction of water increases the compressive strength of sandstone decrease rate increases; higher than $2.551 \%$, with the mass fraction of water increases the compressive strength of siltstone decrease rate reduced.

\section{Reference}

[1] Kang Hongpu.Rock damage by water[J].Hydrogeology and Engineering Geology,1994(3):39-40.

[2] Chang Chun,Zhou Depei,Guo Zengjun.The effect of water on rock yield strength[J].Chinese Journal of Rock Mechanics and Engineering, 1998,17(4):404-411.

[3] Tang Liansheng,Zhang Pengcheng, Wang Yang.Study on fracture strength of rocks with cracks under water action[J]. Chinese Journal of Rock Mechanics and Engineering,2004,23(19):3337-3341.

[4] Tang Liansheng.Study on mechanics and environment effects of rocks under water action[J]. Chinese Journal of Rock Mechanics and Engineering,2000,19(5):681-682.

[5] Huang Xingchun. Rock mechanics[M].Beijing: Higher education press, 2005. 